\title{
PLURALISMO RELIGIOSO Y MODERNIDAD EN LA SOCIEDAD CHILENA*
}

\author{
Arturo Chacón H.
}

\section{PRESENTACIÓN}

El surgimiento manifiesto de una diversidad religiosa en la sociedad chilena de los últimos 50 años, es un hecho que la Sociología de la Religión debe estudiar. Al aparcecer otros sujetos religiosos diversos al establecido, se plantea la cuestión del pluralismo que debe examinarse en relación al tipo de sociedad que se configura.

Esta sociedad denominada moderna ha vivido bajo el signo de la tolerancia de la diversidad, pero aún no ha llegado al nivel de aceptación de ésta. Esto conlleva una preocupación por su desarrollo futuro, ya que, al producirse crisis en el principio organizador que la rigc, la intolerancia aparece con una violencia que a todos sorprende. En otro plano, el político-económico, la sociedad chilena ha experimentado este hecho.

Se trata, entonces, de indagar en las fuentes para ayudar a dar el paso de la tolerancia a la aceptación de manera que el pluralismo religioso lleve a que la modernidad se replantee, en cuanto a su principio organizador de la sociedad.

Luego de un breve recorrido histórico, identificaremos los sujetos religiosos, para, finalmente, examinar la relación entre pluralismo religioso y modernidad en la sociedad chilena y la contribución que esta relación pueda hacer a un arreglo que contribuya a la realización de lo humano en nuestro medio.

Históricamente, el tema plantcado se ubica en forma inevitable, desde el interior del llamado mundo occidental. Este mundo es conformado por el avance de una secta del judaísmo, que se pasó a llamar cristianismo, la que en un período de pocos siglos establece su predominio sobre la lotalidad del continente europeo occidental. Los dioses y religiones de los pueblos de esa parte del mundo cedieron, o se sumergieron, frente al Dios y la religión cristiana. Aunque había una presencia plural de expresiones religiosas, el problema del pluralismo nunca se planteó como tal (esto es, como sistema que reconoce más de un principio último). El cristianisıno avanza en son de conquista y triunfa frente a sus opositores. Durante la Edad Media cualquier intento de cuestionar la hegemonía de la religión cristiana fue duramente reprimido. El Renacimiento, que mantuvo una postura de indiferencia ante lo religioso, y la Reforma, en su cucstionamiento de la autoridad papal, dieron lugar al establecimiento de las condiciones para la tolerancia en el campo religioso. Aunque fue sólo después de las llamadas guerras de religión curopea que se hizo posible la realización de este producto del mundo moderno que surgía. Fue más bien la Reforma Radical, los sectores disidentes de la Relorma del siglo xvi, los que promovieron con más fuerza y persistencia el derecho a expresar sus creencias sin ser perseguidos por la autoridad. Luego de la Revolución Francesa y el surgimiento de los eE.uJ., la libertad de religión pasó a ser un principio generalizado en el mundo occidental. Esto da base al surgimiento del pluralismo religioso en el mundo cristiano y occidental, como principio de convivencia. Se aceptó que las cuestiones de fe y religión eran privativas del individuo y que éste tenía libertad para expresarlas. Esto, entendido como derecho inherente a la persona, se ha considerado como una contribución del mundo

*Ponencia presentada al Iv Congreso Chileno de Sociología, 27 al 29 de agosto de 1992. 
moderno al mejoramiento de las relaciones entre las personas. Por otra parte, se considera que este supuesto avance ha llevado a la indiferencia en términos de los valores primordiales que deben regir la vida y que, por lo tanto, no se puede considerar este desarrollo como un progreso en la vida de las personas.

En lo que se refiere a la sociedad chilena, ambas percepciones se encuentran presentes cn diversas discusiones referentes a aspectos considerados centrales en la vida social, como la educación y la familia, para nombrar dos. Aquí se plantea si el peso que significa el ejercicio del pluralismo va a recaer sobre el mundo religioso como tal o si se va a trasladar al sistema legal y el Estado. Para ello hay que buscar entender aún más lo que significa el pluralismo religioso y sus consecuencias en la sociedad que se denomina moderna.

Está claro, en el caso chileno, que la vida religiosa no ha desaparecido en la forma que se preveía iba a suceder con el avance del mundo moderno. La modernización, entendida como proceso de introducción e integración de la racionalidad económica capitalista en el conjunto social, no ha creado, necesariamente, su contraparte valórica, la modernidad. Por lo menos, no lo ha hecho con la fuerza y persistencia que era de esperar frente a la apertura que la sociedad ha manifestado al mundo moderno del noratlántico. Se han aceptado los frutos de la modernizacion, pero no la modernidad que conlleva.

En lo que se refiere al nivel mundial, no sólo se ha manifestado, en forma persistente, la existencia de un pluralismo religioso, sino que - incluso - se ha desarrollado un proceso de resurgimiento de las religiones tradicionales en la vida de los pueblos. Esto va a parejas, aunque resulte aparentemente contradictorio expresarlo, con un rechazo al elemento de autoridad institucionalizada, en sus diferentes formas, que la vida religiosa ha desarrollado a través de los siglos. Esto es cierto, especialmente entre los jóvenes.

La religión es, a la vez, una manera de vivir y una visión respecto a la vida. Lo último y lo penúltimo ( $\mathrm{P}$. Tillich) se mantiene en tensión. La combinación que las diferentes expresiones religiosas hacen de estos elementos las provee de la identidad frente a las demás. Además, el factor poder: entendiéndose la capacidad económica, organizativa y política, con que una religión enfrenta a otra, es algo a ser considerado en el mundo plural que emerge. Aún más, frente a los integrismos que emergen, también se puede incluir el factor militar. Todo esto juega un papel decisivo en la configuración de lo que consideramos como lo universal. Se discute si lo universal es sólo la extensión de una particularidad, o si todas las particularidades son válidas, por lo que ninguna puede reclamar el carácter de universal ${ }^{1}$. La superación de csta disyuntiva, quizás a través del diálogo, coloca a las religiones en una situación distinta a la que existía anteriormente cuando podían ignorarse impunemente. La situación religiosa mundial actual comienza a tener expresión, aunque reducida cuantitativamente, en la sociedad chilena. Esto, además, de la variedad de expresiones que el cristianismo ofrece en estos momentos, la que se ha incrementado notoriamente en los últimos años.

\section{SUJETOS RELIGIOSOS EN LA SOCIEDAD CHILENA}

La presencia de religiones autóctonas, antes de la llegada de los europeos, merece una discusión separada. De su presencia en el norte sólo quedarían algunos rastros y en cl sur, la religión de los mapuches ha pasado por diversas etapas de expresión y, aún, de reconstrucción. El impacto más

\footnotetext{
${ }^{1}$ Esto, a su vez, lleva a la discusión de si la misión o el diálogo debe prevalecer en la relación con el pluralismo religioso. Ver Gerald H. Anderson y Thomas F. Stransky, c.s.p. (eds) Christ's Lordship and religious pluralism. Varios autores, Orbis Books, New York, 1981.
} 
- :nde que estas religiones tuvieron que afrontar fue el descalabro de su base material y social - snte a la implantación de una forma económica y social que no se basaba en la tierra y su cuidado, mo sustentación de la creencia religiosa. Hoy, al surgir la preocupación por la conservación de : iicrra, estas expresiones religiosas podrían manifestar su contribución particular en un contex to $\therefore$ into ${ }^{2}$.

La llegada del cristianismo tiene, a su vez, facetas peculiares que, de una u otra forma, le dan : mprimen el sello hasta cl día de hoy. El catolicismo español había convivido con el judaísmo y Islam en la península ibérica, por largos siglos, hasta el inicio de la reconquista que busca -ificar a España bajo la égida del catolicismo. El éxito obtenido en esta empresa culmina con la xpulsión de los judíos y musulmanes. Coincidente con este hecho se da la posibilidad física de xpansión a las nuevas tierras que Colón entrega a la Corona española. España adviene como aperio en los albores de la modernidad. Al presentarse la Reforma y el Renacimiento en la Europa de entonces, el cristianismo español asume la postura de la Contrarreforma. La unidad $\therefore$ Ligiosa y la del Estado que ha surgido se entremezclan, como sucedió también en otras formas $\because$ los emergentes Estados-Naciones del mundo moderno que nacía. Este catolicismo de contra-: forma llega en tren de conquista al encuentro con las religiones de esta parte del mundo. adudablemente hubo voces y personajes que manifestaron la conveniencia de lo que hoy zunamos diálogo. Los jesuitas fueron los que más lejos llegaron en el intento de resolver los - omplejos problemas de la base material y los aspectos religiosos que podían acomodarse en el -ristianismo de nuevo cuño que emergió en los tiempos modernos. La identidad cultural que se - asa en el desarrollo de este catolicismo se la busca reproducir hoy, a pesar de las influencias osteriores de otras experiencias católicas venidas de diferentes partes del noratlántico. De aquí i atirmación de la existencia de un sustrato católico en la cultura del continente que estaría todavía resente ${ }^{3}$.

Por lo que se refiere a la llegada del cristianismo evangćlico-protestante éste se puede aracterizar, básicamente, con la configuración establecida por la Reforma Radical y no con la Reforma europea del siglo xvi. Aunque existe una presencia de esta Reforma a través de los grupos inmigrantes, fueron los sectores disidentes de la Reforma los que, estableciendo primero su presencia en EE.UU., llegan a Chile con los inicios de la República (congregacionalista, metodista bautistas, principalmente), dando origen a la presencia del cristianismo evangélico-protestante en el país. En este siglo, con la división de la Iglesia Metodista en 1909, da origen al movimiento evangélico pentecostal que es la gran mayoría de este sector en la sociedad chilena. Estudios recientes sitúan al mundo evangélico protestante en un $16 \%$ de la población del país ${ }^{4}$. No habiendo Jatos censales respecto a religión en 1982 debemos trabajar con cstos estudios parciales para identificar a los actores religiosos en la sociedad chilena.

Las fuentes citadas nos entregan:

- 74\% Católicos

- $16 \%$ Evangélicos-protestantes

- $1,1 \%$ Mormones;

${ }^{2}$ Ver Fernando Mires. El discturso de la Naturaleza. Ecología y Política en América Latina. Editorial DEI. Costa Rica, 1990.

${ }^{3}$ Ver al respecto "Sustrato católico" en Breve diccionario teológico latinoamericano. Ediciones Rehue Ltda. Santiago, Chile, 1992, pp. 333 y siguientes.

${ }^{4}$ Arturo Fontaine Talavera y Harald Beyer, "Retrato del movimiento evangélico a la luz de las encuestas de opinión pública" en Estudios Públicos, № 44, Primavera, 1991, págs. 63-124. Véase también Humberto Lagos Schuffeneger y Arturo Chacón Herrera, Los evangélicos en Chile: una lectura sociológica, Ediciones LAR-PRESOR, 1987. 
- $2 \%$ Testigos de Jehová;

- $0,2 \%$ Otras religiones no cristianas y

- $6,6 \%$ Sin religión.

El sector que crece más rápido, a una tasa anual de $4,8 \%$ en los últimos diez años, es el evangélico-protestante, en todas sus variantes. La presencia de sectas tradicionales (Mormones y Testigos de Jehová) son los grupos más grandes de presencia de otras expresiones religiosas no cristianas, con un total de $3,1 \%$ de la población. Finalmente, hay que agregar aquí que cl sector que declara no tener religión no varía de acuerdo al tradicional 5,0\% que arrojaron los censos hasta 1970. Esta medición de pertenencia religiosa nos demuestra que existe un pluralismo religioso al interior de la sociedad chilena. Sin embargo, este hecho requiere ser examinado más a fondo con el objeto de establecer su relación con la modernidad y las futuras tendencias a que pueda dar lugar en la configuración de lo social.

Mirado desde el punto de vista de una teoría de la secularización, como marca de aparición de la modernidad se postula el decrecimiento de la pertenencia religiosa de la población. En el caso chileno, en su gran mayoría, la población adhiere a alguna organización religiosa, por lo que, en una primera aproximación, se pucde afirmar que la secularización de la sociedad no se ha manifestado hasta ahora. Por el contrario, se afïma que el carácter religioso de la población es una defensa frente a las incursiones que la modernidad intentaría realizar.

Aquí se plantea el problema de la transformación cultural que conlleva la modernidad. El cristianismo, tanto en sus inicios como en otros períodos históricos, ha sido factor importante, si no decisivo, en los cambios culturales que se han producido en las sociedades donde ha llegado en profundidad. Habría que postular si existe en la sociedad chilena una confrontación radical entre religión y sociedad. Al no comprobarse esta confrontación queda libre el camino para ser reemplazada por la aparición del pluralismo, lo que ha acontecido. La pregunta subyacente es si la religión (organizada) puede, ahora, llevar a cabo el papel de expresar posiciones con un carácter de exigencia total a la sociedad. La aparición del pluralismo parece eximirla de esta necesidad, por lo que podría postularse que queda así liberada para participar, críticamente, en la reformulación de los parámetros culturales emergentes.

\section{PLURALISMO RELIGIOSO Y MODERNIDAD EN LA SOCIEDAD CHILENA}

La implantación del pluralismo religioso en la sociedad chilena libera a las iglesias de la necesidad de formular demandas con carácter de obligación gencral para aquélla. Las orientaciones que puedan dar, relativas a la dirección de la vida, aparecen como una contribución más, frente a otras posibles orientaciones ${ }^{5}$. Las orientaciones ideológico-políticas e ideológico-económicas también tienen que ajustarse a esta situación de pluralismo en la sociedad, discusión que habitualmente se presenta bajo la expresión de búsqueda de alternativas. Si el pluralismo es un componente central, e inherente a la nueva configuración cultural, queda planteado el problema de la articulación de orientaciones que den dirección y visión a la sociedad como un todo.

Una primera observación es que los intentos totalizantes no tienen cabida en la nueva configuración. Esto no significa que no hayan enunciados que no aspiran a ser la respuesta al devenir de la vida. Sin embargo, éstos no pueden pretender ser parte de una articulación como

\footnotetext{
${ }^{5}$ Ver Trutz Rendtorff "En torno a la problemática de la secularización. Sobre la evolución de la sociología de la Iglesia a la sociología de la religión", en Joachim Matthes. Introducción a la sociología de la religión. Alianza Editorial. España 1971. 'Tomo I. Pägs. 221-244. También Phillip E. Hammond, "Religious pluralism and Durkheim's integration thesis" en Allan W. Eister (cd) Changing perspectives in the scientific study of religion, John Wiley and sons, New York, London, Sydney, Toronto. 1974, págs. 115-142.
} 
$\therefore$ ¿s. La sociedad ya no se define dentro del horizonte de los problemas vitales que la aquejan en $\therefore$ minos generales, sino por la relación entre las diferentes orientaciones que reclaman atención a que consideran su misión irrenunciable. Se da, entonces, un tráfico entre los grupos que -stentan las diferentes orientaciones, que puede ser intenso, o no, dependiendo de las condiciones -12 existan en un momento dado.

En lo que se refiere al mundo religioso, esta nueva situación permite que salgan a la luz -uellos componentes de su autocomprensión misionera, que estaban subyaciendo mientras la igión (organizada) buscaba extenderse universalmente (tanto geográfica como culturalınente). Ėta pretensión de universalidad, surgida de la experiencia europea del cristianismo, se frustró . $\therefore$ da). Esta actitud, por cierto crea condiciones negativas para el proceso de desarrollo de una mprensión pluralista de la sociedad y de la realidad.

Un punto crucial, a vía de ejemplo, que tiene que ver con el desarrollo de esta nueva nnfiguración es la autocomprensión que existe en cuanto al ministerio (en este caso, de las -lesias cristianas). Iría quedando en el pasado su comprensión de ministerio-autoridad para dar - iso a otra, de ministerio-servicio. Esto no es nada nuevo en términos de los orígenes del :istianismo, pero el desarrollo histórico sumergió a este último en beneficio del primero. Ahora żtán las condiciones, de aceptarse la realidad del pluralismo, de hacer renacer la otra autocom- rensión. También surge la posibilidad de rescate de una visión frente a la vida, que no se liga ¿sesariamente a la sobrevivencia de la organización-autoridad. Cristianismo en sociedad y no - iesia y sociedad sería la resultante de la nueva relación.

Llegamos así al punto que se discute frente a la necesidad de integración (orden) de la riedad. La tesis clásica de Durkheim es que la sociedad debería realizarse como "una sola munidad moral". Esto se ha entendido como que, para realizar esto, en una sociedad debe existir na sola religión a la cual sus miembros pertenecen o adhieren. Por razones políticas, esta iñnación se entendió, y practicó así, en el desarrollo del cristianismo en Europa, incluso con osterioridad a la Reforma.

El plural ismo religioso, entonces, sería una amenaza para la integración de la sociedad. Como han sugerido diversos autores Durkheim estaba más preocupado de la unidad de la sociedad noderna que de la religión. Además, que esta unidad de la sociedad moderna adquiere un carácter - ligioso, pero que ni es la religión la que lo lleva a cabo, ni tampoco es la religión la que le da la - ohesión a la comunidad de interés y tradición que lleva a la unidad moral que él buscaba.

De todo esto se desprende que lo anteriormente era unificado por la religión, la sociedad moderna lo hace a través de otras instituciones, especialmente la legal. La heterogeneidad de zrupos, no de individuos, es lo que se enticnde por pluralismo religioso, y lo que se entiende por Jentidad no es tanto la etiqueta que tenga el grupo sino cómo realiza lo que da sentido a sus vidas mitos, teología, actitudes, visión de mundo, entre otros).

Al estudiar el pluralismo religioso se advierte que la existencia de diferentes grupos corresonde a la historia diferente de donde provienen y que comparten como grupo. En este sentido la sxistencia de grupos religiosos evangélico-protestantes en la sociedad chilena se debe, en gran medida, a que comparten y recogen una experiencia histórica que no se encuentra en la religión hasta ahora predominante. Su aparición se corresponde con momentos históricos en que se zuscaba definir la comprensión del devenir histórico de la sociedad chilena. Recoge, para ello, slementos e instrumentos que se encontraban en la tradición popular, junto a idearios que, importados o no, le permiten articular una nueva comprensión del sentido para la vida de todos os días. Se rescatan así subjetividades que yacían latentes, tanto en el ideario cristiano, como en .a tradición secular popular. 
En otro orden de significado en la sociedad chilena, el positivismo que, sin duda, ha ejercido una gran influencia cultural el período republicano, se manifestó en la oposición religión-sociedad, que buscaba la secularización, no sólo del Estado, sino también de la sociedad ${ }^{6}$. Al disolverse este pretendida confrontación, que hemos ya examinado, historicamente en 1925, el positivismo no puede seguir jugando el papel de defensor de la sociedad frente a la religión, precisamente porque la separación Iglesia-Estado da, ahora, lugar al pluralismo social y religioso. También se puede entender así el surgimiento de grupos político-ideológicos que buscan desempeñar un papel en la gestación de la sociedad que nace en pluralidad.

La dificultad con el desarrollo del pluralismo religioso y sus posteriores consecuencias de sentidos en pugna, es que se produce un traslado desde Ia religion (organizada) al Estado de la orientación de sentido para el conjunto social. Esto es lo que hemos venido llamando el papel que entra a jugar la ley, o lo legal, en la nucva configuración. La obligación generalizada frente a determinadas conductas que se exigen, son ahora entendidas como proviniendo de este nivel institucional. En esta situación se ve la contradicción de que la religión (organizada) es menos religiosa, mientras que el Estado y la ley empiezan a adquirir una calidad religiosa. En los países que han ido más lejos en esta dirección, que son las democracias occidentales, se percibe esto de tal manera que, incluso, en uno de ellos se habla de religión civil (EE.UU.). Queda la cuestión que se plantea respecto al papel legitimador de la sociedad moderna que le iría quedando a la religión. La religión (organizada) busca todavía reservarse este papel buscando autonomía para sus organizaciones, frente al Estado y la ley. De esta manera busca la independencia necesaria para jugar el papel de sancionar negativamente, la mayoría de las veces, o positivamente, las orientaciones, actitudes y conductas que puedan surgir desde el Estado y la ley. No cabe duda de que este papel (des) legitimador es funcional al ministerio-autoridad, pero no es necesario para el ministerio-servicio. Aquí, más bien, se buscaría una integración de la orientación religiosa con elementos, incluso no religiosos, de la cultura. Esto, al mismo tiempo que se establece una interdependencia estructural con otras partes de la sociedad ${ }^{7}$. En la sociedad moderna esta última opción tiene una posibilidad mayor de ejercer, no tanto una influencia sino de contribuir a su orientación generando la visión común y la dirección para la vida de todos los días ${ }^{8}$. A su vez, esta actitud permitirá que la religión no se perciba sólo como contribuyendo una ética, o parte de ella, al quehacer social, sino participando en la construcción de una visión común y la orientación para la vida.

La modernidad pretendió vivir sin religión. Esto se refería a la religión (organizada) con sus pretensiones de universalidad y autoridad. De darse otras condiciones, como las que vemos incipientemente en la actualidad, la sociedad podrá vivir la modernización y contribuir a redefinir la modernidad para este páís, con su historia y sus tradiciones, las que ahora estarían siendo recogidas en su totalidad, precisamente debido al desarrol lo del pluralismo religioso, especialmente. Sin duda hay otras expresiones del pluralismo social que también estarían en esta tarea, pero su tratamiento va más allá de lo que hemos propuesto para esta ocasión.

Finalmente, queda la tarea de articular las diversas expresiones que expone este pluralismo, lo que se transforma en el desafío actual en la coyuntura favorable que vive el país para realizarla.

\footnotetext{
${ }^{6}$ Ver los sugerentes estudios en Catolicismo y laicismo. Las bases doctrinarias del conflicto entre la Iglesiay el Estado en Chile 1875-1885. Varios autores. Ediciones Nueva Universidad. Pontificia Universidad Católica de Chile, Santiago 1981.

${ }^{7}$ Ver Richard K. Fenn "Religion and the legitimation of social systems" en Allan W. Eister (ad), op. cit. Págs. 143-161.

${ }^{8}$ En la relación con la "Evangelización y modernización en Chile". He desarrollado este punto en Teología en Comunidad, № 8 .
} 